\title{
A Long Anthropological Perspective on the Humanities.
}

\section{David Clifford}

How interdependent are the sciences and humanities? In this article I trace, in broad terms, a scientifically-grounded narrative that culminates in a world we describe using the humanities, and my field, literary studies, in particular. The longstanding presumption that science sits opposed to the humanities is fostered on both sides, to neither's benefit. I hope that by describing something of the bilateral relationship between these fields, arguing that they may be points on a web rather than discrete disciplines, we might better appreciate their places in a cultural ecosystem of interdependence. My hope is that scholars in both the sciences and the humanities appreciate better what one offers the other.

Several scholars have pondered upon the role of the humanities recently. Helen Small reviewed arguments that arose in the nineteenth century from Jeremy Bentham and Samuel Taylor Coleridge, via John Stuart Mill, and from Matthew Arnold, among others. Jonathan Bate's collection of essays by various humanities scholars perhaps shows even more awareness of the pressure on the academy to justify its receipt of public funds, again on cost-benefit principles. Stefan Collini (What Are Universities For?) and Martha Nussbaum have weighed in on similar terms. My own position is largely sympathetic to all of these: Small's is a historically well-informed discussion of the kinds of value that may not be pecuniary, but which are socially significant nonetheless; Nussbaum repudiates the demand for economic value in and of itself, though this may be preaching to the choir, rather than those actually in charge of funding the choir; Bate's various essayists are likewise persuasive, but many of their essays read to me like research proposals to funding bodies, anxious to trumpet past financial returns from research into archaeology, classical studies and theology, with the promise of more if funding continues (the principal object of gratitude in that volume's acknowledgements is the United Kingdom's Arts and Humanities Research Council). Unlike the essayists in Bate's collection, I do not feel I can make much of a case for enhanced, or even continued, public funding. But if their arguments rest on the observation that the benefits of humanities research are often entirely unpredictable at the point of departure - which I would observe is also true of some of the most significant scientific research - then highlighting some of the unexpected consequences of language as an adaptive characteristic, challenging some of the ways that language is routinely taken for granted in our disciplines, might raise the idea of its value more widely, validating its continued study as a driver towards social good.

This article emerges from discussions I have had over the years with English students at Cambridge, recounting their experiences of the flurry of introductions that constitute Freshers' Week, where they so often face demands from students taking STEM subjects to justify the academic value of English. After an exhausting series of evenings being tormented by, say, one of the new intake of engineers, who has pointed out that the raw study of poetry has little saleable value in the marketplace, that all degrees encourage critical thinking and how to write; that they read books too, only in their leisure time, after they have finished their studies - at this point I propose to my weary students that they abandon the defensive mode and strike up a stealth attack, beginning with a question - "You've heard of Charles Darwin?" (Because if my English students are going to be patronized, they may as well give a taste of it back.) Anyway, 
assuming our engineer splutters back "Of course!", the next question he faces is, "Do you know what Darwin considered humankind's second greatest achievement?" And maybe he will, but that is unimportant: the actual answer (which is the control of fire) is not the point. The point of this loaded question is to prompt him to demand what it was Darwin considered to be humankind's greatest achievement. "Oh," my student will reply nonchalantly. "The evolution of language" (Darwin, 1:137).

Controlling fire provided the survival essentials and evolutionary drivers of security, socialization, cooked food, an energy source that is not human muscle, and the only pathway to advanced technology. Language, however, is the critical means of managing its power, passing crucial information across huge distances and between generations, organizing and maintaining large social groups, and securing advantage while lowering the risk of self-destructive violence. Darwin knew that language was an evolutionary adaptation, and we all know that human language exceeds anything like it elsewhere in the animal kingdom. The aim of my examination into how language emerged concomitantly with social and technological adaptations is to throw some additional light on the interdependence between the sciences and humanities. Within the aims of the ScienceHumanities more broadly, I propose that this interdependence is not only mutual, but that it has been so throughout history, and that both our social and technological progress would never have evolved without it being so.

I should say in advance that $I$ do not know how advanced language evolved among the Homo species. The surviving palaeontological and archaeological evidence is too fragmentary, and narratives based upon it require a lot of imaginative gap-filling, about which no-one fully agrees. But I will adopt certain positions about it from among current thinking, supported by evidence, which I hope will not be too controversial. The first is that language is an evolved human characteristic. We cannot remotely assume it has always been part of us, nor that we developed it because we chose to. Like the peacock's tail, language was always far too extravagant a luxury to have evolved without returning significant evolutionary advantages.

The second point, slightly more contentious among linguists, is that the evolution of language was gradual rather than sudden, that its origins more likely emerged at least in rudimentary form in australopithecines (c. 3 million years ago (3mya)) and Homo habilis (c.2mya), and evolved as the various species of Homo evolved, rather than, as some Chomskyans claim, as a sudden process some time in the early emergence of Homo sapiens (c.200-300,000 years ago (200-300kya)). The third, more in agreement with the Chomskyans, is that language ability is largely innate rather than learned from scratch by every human child (Pinker Language Instinct, 21-24). But these are, as I say, adoptive positions, and neither scientists nor linguists (which I am not) are settled on them. That may be an advantage of being a humanities scholar: to work comfortably with the balance of probabilities rather than empirical certainty.

I will begin by proposing that human language is like colour vision or gripping hands: the refinement of some survival/reproductive adaptation that has taken on functions beyond its original reason for evolving. Biologists call a feature that takes on a function for which it did not originally evolve "exaptive". Birds' feathers, which evolved not for flight but for some function such as temperature control or courtship display, are the classic example of exaptation - flight is a relatively recent adaptation, yet this conversion of feathers' function would have been evolutionarily impossible unless feathers were well established features of flying birds' ancestors. Our thumbs are another example. Thumbs are useful, for sending text messages or playing on game consoles, or hitchhiking, but we could not possibly have evolved gripping hands because of a future wish to do these things. We have gripping hands because our 
ancestors once needed to be secure and mobile in treetops; the unparalleled fine motor skills that distinguishes $H$ sapiens from other hominids arose from the survival and reproductive advantages conferred by the manufacture of precision tools. Complex language likewise evolved to fulfil different functions from how it is used today. To anyone with minimal knowledge of evolution these facts ought to be obvious, though even then, according to Dutch primatologist Frans de Waal, assumptions about the preeminence of human uniqueness, including but not limited to language ability, are pretty common even among scientists (de Waal 157-58, 187-88). Among non-linguist humanities and literary scholars, human language ability as a given quantity seems all but taken for granted. We talk a lot about how language shapes ideology, which of course it does, but this has set aside the ways in which language evolved as a responsive adaptation to environmental pressures, and how, since then, environmental pressures exerted by changes in technology, polity and scientific thinking, allowed language to move into new spaces for which it did not originally evolve, just as thumbs did.

I am aware that this recasts society and ideology as environmental pressures this is deliberate. Refocussing on ecological contexts recalls the role played by language in human social development. It enhances our understanding of the interplay between language and environment. We cannot quite give up our addiction to the problems of genius, or of Whiggish intent, when these are actually post hoc judgments after some new way of doing things or of seeing the world seems preferable to what went before. Examples might include the discovery of perspective, or narrative forms, or even evolutionary theory itself. But such new ways of seeing are generally not consciously aimed at eliminating an old way of seeing the world, any more than the point of CDs was to make vinyl records obsolete. Behavioural ecologists study the means by which environmental pressures create selective adaptations that ultimately embed in species as behaviours, and I doubt many biologists would claim that advanced language ability was merely an agreeable add-on to a reasonably bright primate. As humanities scholars we are often inclined to start our arguments from the position of language as a given: like feathers and thumbs, language always seems to have done what it is doing now. But this is true for none of these.

I shall begin by reviewing, then, the idea of language as a uniquely human characteristic. It seems strange, in an era where literary scholars increasingly strike ecocritical positions towards texts, and are discussing concepts such as the post-human, that the relationship of human language to the means of and reasons for communication among other species does not capture their attention in the same way. Humankind itself, including its language ability, is merely another development from ancient ecological conditions, after all. Nothing in evolution emerges from nothing, and this includes language: our species' antecedents were not merely similar primates whose more complex communication was primarily through actions and gestures - we think of apes grooming, offering their hands in observation of hierarchical positions, and their facial expressions. Chimpanzees use limited vocal sounds to pass on information to each other about the environment. We know, however, that no chimpanzee can master the complex speech mechanisms we have evolved, nor can they ever manage the conceptual complexity of human language. This is partly physiological: other primates are physically incapable of ever perfecting the fine motor skills needed for breath, mouth and tongue control. It is also partly cognitive. Sign-language and symbol-based studies - for instance, "Nim Chimpsky", the subject of James Marsh's 2011 film Project Nim - have observed chimpanzees communicating to the level of a reasonably bright threeyear old human child, but not beyond (Pinker, Language Instinct 335-42). Apes can also conceptualize abstractions such as liking, or absence, or feeling sorry. Although 
there is significant evidence that higher apes experience some of the complex emotional responses humans like to think of as their own, such as guilt, a sense of injustice, and regret, these are only ever clustered under the blunt abstraction of being bad. But primatologists have observed primates exhibiting acts of communication which advance their own interests, or those of the group, which while unsophisticated in themselves, suggest some of the complex underlying cognitive processes that Homo sapiens expresses through more refined means. Behavioural ecologist Brandon Wheeler, during fieldwork in Argentina, observed tufted capuchin monkeys competing for bananas - a highly prized food - that fieldworkers had left out for them. Highranking monkeys gorged freely on the bananas, while low-rankers were kept away. But occasionally, low-rankers gave the verbal warning signal for wildcats, causing those eating to scatter - even though there was no cat approaching. Low-ranking capuchins would then seize the chance to grab temporarily abandoned bananas before their deception was realized (Wheeler). Similar acts of deception have been witnessed in chimpanzees (de Waal 130-31). Though rudimentary, such episodes demonstrate the function of language as both information exchange for the benefit of the group meerkats, dolphins, elephants and bees do this too - and misinformation for the benefit of the individual.

Humans and capuchins last had a common ancestor about 35mya; humans and chimpanzees about 7mya, and a lot has happened on our branch of the split to get us where we are. We cannot assume that the behaviour described above would have been present in those last common ancestors, but we can see that seven million years down the line there are elements of similarity in how and why our related species communicate. Merely thinking of primitive language as information exchange, whether that communication is vocal, gestural or facial, as the story of the capuchins suggests, is to underplay the complexity of non-human language users' motives. By the time we get to the higher primates, communication has subtler, and possibly more nefarious, purposes. Which is where we get to Homo sapiens - about 200kya (although see Hublin).

Further contributory factors in the evolution of human language include early hominids' movement from closed-canopy forests to woodland savannahs, hominins' discovery of root-based sources of stored carbohydrates, a shift to more meat-based diets and, argues Richard Wrangham, cooking that meat first (Wrangham \& Peterson 45-48, 52-57; Wrangham 38-44, 95; Herculano-houze 187-98). For Edward Wilson, socialization was critical to our primate ancestors because as we relied more on intelligence to secure resources we became increasingly weak and vulnerable to our predators - high-density calories can be converted to muscle or brain, but not both. The safety of numbers protected us; but socialization among intelligent, competitive individuals (compare primates with herding, ruminant bovine species) is harder because each other individual at close quarters represents another obstacle to one's own access to resources. Social species have to cohere or lose the advantages of being in a group, and other individuals are not always easy to get along with (Wilson). Compared to most species, including our closest relatives among the great apes, humans are astonishingly social. Orang-utans, our most distant cousins among the great apes with a common ancestor not less than 10mya, hardly have anything to do with each other, especially males. Humans live in tribes and cities and nations, and almost every decision we make has a social component, an adaptive distinction from other species we take for granted.

The world Wilson describes is one in which early humans, especially once they had controlled fire, settled into more socially cohesive groups. Fire appears to have been in regular use by humans since around 1.5 mya, probably at the hands of $H$ erectus 
(2mya), and considerably before the emergence of $H$ sapiens, who evolved more than a million years later (Wilson 47-48). Fire deflects potential predators, and if you control a fire with enough care, it remains static, which keeps a lot of formerly mobile humans in one place for a lot longer - the precursor to settlements. Chimpanzees spend many hours every day each scouring a wide area for their own food (they also each make a new bed every night), and then more hours - up to seven, Wrangham reckons - just chewing and digesting the tough, fibrous leaves (Wrangham 138-42). If you cook food first, it takes nowhere near the chewing or digestion, and energy is released from it far more efficiently, putting longer gaps between meals, all spent around a fire with lots of other humans with time on their hands. One cannot imagine why an orang-utan would evolve such an absurdly expensive luxury as complex language, for his occasional interactions with other members of his species, most of which involve either sex or fighting. Humans, on the other hand, developed in increasingly complex social environments where selection pressures gave preference to individuals who communicated, got on, contributed to the band, worked cooperatively and actively ingratiated themselves with others.

Evolutionary anthropologist Robin Dunbar proposes that the imperative to get along in groups fed into the origins of language by way of grooming. Grooming serves as a crucial bonding mechanism between primates, who use it to show affection or deference, make peace, form alliances or, when withdrawn, to express displeasure. Larger groups required more individuals to keep on good terms, meaning more time grooming rather than seeking food. Eating cooked food frees time to spend socializing and grooming, but can also create even larger groups to keep happy - and one can only groom one individual at a time. Dunbar's theories are not without their critics, but they are most persuasive for me. He argues that over time the soothing coos used by a groomer may have extended into a wider meaningful range, becoming verbal grooming. Grooming by sound as well as touch meant that more than one ally could be maintained simultaneously, and the process could even be simultaneously reciprocated (Dunbar 7779). Thus, communicative speech.

There is an opening here for particularly gifted communicators, especially if it conferred advantageous reproductive rights. Highly developed language skills are attractive to most humans, but a lot of what humans say must be taken with caution, because the best communicator may also be a crafty manipulator. Time-heavy interaction with other humans is the evolutionary trigger behind the evolution of language - and if they are not to be left behind, all parties must be very good at all parts: speaking, interpreting, and the art of detecting a liar.

In his 2014 book Sapiens, Israeli historian Yuval Noah Harari charted humankind's ascent to world domination. He argues that what distinguished us from variant hominins, and what gave us pre-eminence over them, was our capacity to believe things that were not true (Harari 24-25). Examples of such fictions include the existence of gods, creation stories, characteristics of a tribe, nation or culture, the value of money - any idea around which humans can mobilize for common purposes. Chimpanzee troupes in the wild do not exceed 150 individuals, and their organized hunting parties number about twenty, all known to each other personally, usually very well. But humans organize themselves into hundreds, thousands, tens of thousands, mostly strangers, united only by their belief in some common purpose - America, Christianity, the Olympic Games, human rights, the March for Science - assigned arbitrary value by its adherents. Therefore, converting the world into fictions, formulating responses to those stories, and sometimes binding ourselves to those stories in pursuit of harmony as a social species, has been fundamental to the development of 
civilization. It may also be the case that many of the stories that bind societies have enabled humans to engage in prolonged, large scale wars, crusades, invasions, jihads and genocides, but that hardly diminishes the importance we might lay on understanding the processes behind narrative, rhetoric, and the formation of myth.

There are further relevant corollaries to consider regarding the development of language. The focus of English studies is, necessarily, on the written word, and written language dates back to around 3200 BCE. That was when Sumerian scribes allocated shapes to the phonemes of their spoken language, which they then used consistently to inscribe information that the initiated could convert back into spoken form. Therefore no human utterance more than 5,500 years old exists in written form, across all cultures. But palaeontological evidence points pretty firmly to sapiens using the same complex language skills we have today for at least 75,000 years (with a reasonable case for going back to our origins c.200kya), and this being one of the drivers that actually separated our branch from at least six or seven other species of Homo with whom we then shared the world. Some palaeontologists have proposed that $H$ naledi (c.300kya), $H$ neanderthalensis (c.500kya) and even $H$ heidelbergensis (c.600kya) were anatomically (if possibly not cognitively) suited to forms of speech. Given that all these species used fire, and that fire use demands sophisticated information exchange about collection or construction, ignition or transfer, maintenance, and safety, such forms of language in Homo species prior to sapiens is virtually certain, and relatively complex language more than plausible (Mithen; Fitch).

Even taking the lower figure for sapiens, we can count on there being 75,000 years of human stories, memoirs, myths, songs, lullabies, epics, religions and jokes that were lost forever when the last human who knew them closed her mouth for the last time. In the 1920s the American Homer scholar Milman Parry proposed that the story of the Trojan Wars (c.1200 BCE) was passed down in song by generations of poetminstrels with remarkable memorization skills, with no mind for its publication or care for preserving the fidelity of what they inherited if they could improve it in some way. The act of inscribing The Iliad onto clay froze that organic, multi-authored song, refiguring it as something scholars took as definitive, as we might describe the authoritative text of Middlemarch. Modern English scholars should beware not to overlook the fact that stories began not as transmissions into the future for us to ruminate upon, but between contemporaries.

And let us remember also how astonishing and powerful the written word was for its early adopters. Societies with the power to write down their stories knew at once that it gave them power. Writing survives the death of its creator; it was literally understood as a form of immortality. For individuals, this might be (and often was) narcissistic, but for communities, inscribing formative myths elevates and preserves them (Greenblatt). There is a reason religious texts are reverentially referred to as script-ure, and that scripture by itself - the fact of being written down, in a world where only the most important things acquired that status - denoted authority. When God comes to Jeremiah to speak of the restoration of Israel, the first thing God tells Jeremiah is to write everything he says in a book (Jeremiah, 30:2). The New Testament is saturated with instances where "It is written" confers unique authority to a pronouncement (too many to enumerate, but extensively in Matthew 4, Luke 4, Romans 2-4, 1 Corinthians 1-4). Religions worldwide hold the written documents of their foundation myths, the physical artefacts themselves, to be literally sacred. Jews keep all holy documents, however old and worn, in a safe place in the synagogue (a genizah) until they can be given a full Jewish burial. In Islam, it is haram to damage any document bearing text from the Koran. Sikhism elevated its scriptures to the status of 
the eleventh and final living guru. This elevation of the authority of stories converted from ordinary spoken to permanently written form is a continuation of the bedazzled awe with which Bronze Age civilizations first regarded the magical new technology of inscription. Merely recalling these details should restore to us the colossal value writing has had in the development of our civilizations, and why its effects matter so much more than the mere transference of information.

What does this mean for literary studies? We should perhaps reflect on the value of language, story-telling and writing as instrumental in mobilizing well-organized societies in large numbers against neighbouring societies, to regard their own (but not others') foundation myths as sacrosanct, and to crystallize gossip and personal information about individuals long past the point at which the Earth would have turned their bones to dust. We might counter that the study of history is dominated by the tribal violence and slavery that persist like a background hum behind human affairs; the study of art is contaminated by icons of religious adoration and wealthy patronage; science by technologies of destruction; and engineering by the infrastructures of invasion and subjugation. Of course, no-one disputes that these disciplines have taken more lifeaffirming, exaptive, directions, which among the humanities have been relied upon by defenders such as Bate and Nussbaum. What of the civilizing effects, in a much larger sense than usual, of literary studies? Students of literature may be told that poetry is important and good for them, but one either likes or does not like poetry. All that unpicking and interpretation is a lot of work just to get to a message that could have been expressed with a lot less fuss and technical showing off. What is poetry for, but the vanity of those who write it, and the self-satisfaction of those who read it?

The answer for me lies in language's socialization capabilities, in its smooth communicators by whom others want to be verbally groomed. Chimpanzees experience quite complex inner lives, and dogs, crows, elephants and dolphins all may have at minimum a rudimentary sense of empathy (de Waal). But just as humans exceed other species in language and tool use, we understand the experiences of others of our own by orders of magnitude. This, I propose, is thanks to poets, or those proto-poets who first mastered the subtleties of verbal grooming - who created poetry before they realized they were poets, just as Daniel Defoe wrote Robinson Crusoe without realizing it was a novel: Palaeolithic mothers cooing the pleasures of rhyme and rhythm to language-absent infants; ancestral storytellers accumulating peer approval (and very likely reproductive privileges) by demonstrating pleasurable inventiveness of language (Migliano et al); friends and lovers cementing emotional bonds, or leaders rousing warriors to defence or conquest. The study of such language means delving to the core of an emotional or psychological experience; filtering away, as a scientist would, whatever it is not, to uncover something essential, then ideally expressing it in some form which conveys to another the nature of that experience.

Chimps experience sadness, even grief, and can be remarkably good at comforting friends. But sadly for chimpanzees, the essence of sadness itself is inevitably broad. This can be so for humans, who may settle for "I'm fed up!" to express their situation. We all get fed up, so we understand what it means when someone says this. But consider William Wordsworth, unexpectedly noticing something amusing, turning to show his beloved infant daughter Catherine whom he knew it would delight, and then remembering that she was dead. And that he had already buried her.

Surprised by joy - impatient as the Wind

I turned to share the transport - Oh! with whom

But Thee, deep buried in the silent tomb, 


\section{[...] how could I forget thee?' (204)}

This describes the nature of grief, in its agonizing complexity; Wordsworth's bewilderment at memory's cruelty, such that the intricate texture of the experience is transmitted to us. We know from those lines more than that Wordsworth was merely sad. The poet gives us something intimately personal against which to measure our own inner lives. When we find correspondence, when a poem reflects back something of ourselves, we realize the capabilities of language beyond its value as mere information exchange, or even gossip. Poets enable us to see how like one another we are experientially. Anatomists cannot do this. Only poets. This is what binds the community of humankind. This is the value of poetry.

I will conclude by touching on another idea, raised by Harvard psycholinguist Steven Pinker in his 2011 The Better Angels of our Nature. Habitual and routine violence were commonplace until the European Enlightenment, Pinker claims - all Elizabethan men carried knives, Christopher Marlowe took one in the forehead over an argument about a tavern bill, and blunted table knives were invented expressly to keep daggers away from the table, where they were prone to be used malevolently (see example of Marlowe, above). Despite everything in the contemporary news media, violence today is a minuscule fraction of the levels former societies regarded as normal, which Pinker attributes to a variety of factors, including friendly commerce, a decline in honour codes, a decline in utopian ideologies, formal marriage, an understanding of individual rights, feminism, and literacy. The novel is an eighteenth century invention largely driven by improved technologies in paper production, printing, binding and distribution, but also by widening literacy, which was crucial for extending the novel's reach. A larger readership and vastly more well-crafted novels resulted in more readers encountering the problems, emotions and inner lives of other people-even if they were fictional - than they ever could in everyday conversation. Novels are detailed renderings of what it is to be another person. We measure them against ourselves and our own private concerns, and if done well the gap between our own being and those of others becomes marginally smaller. If dehumanizing others makes it easier to hate or harm them, then restoring their humanity, their likeness to us, makes it harder. This is a claim Pinker makes for the novel, which I rather approve (Pinker Better Angels of our Nature 175-77). Novels have made it harder for us to kill each other. What might always have seemed intuitively true about language's (and literacy's) essential roles in refining our civilizing tendencies takes a more concrete form as the story of its evolution unfolds.

Technology moves fast, and we are prone to forget very easily the stages between rudimentary and advanced forms, even over short time frames - a lament often heard from scientists, asked to justify their research by predicting its value for the future. Over the longer term, those intermittent stages can disappear almost entirely into the background noise. In this article, I have traced the long-term mutual interdependence between the interests of the sciences and the humanities, and how their interactions may, like the intermittent stages of scientific progress, easily be overlooked if our attention drifts. Specialist mathematical models designed by Australian physicist John O'Sullivan in the 1970s, to sharpen radio signals detected from disintegrating black holes, were never predicted to form the basis of WiFi technology - though that is where those models were eventually put to principal use. In like manner, and over a much longer term, the consequences of song, poetry and stories coevolving with, and facilitating, the technologies of human civilization could never have been predicted at its outset. Critical to the ScienceHumanities is an understanding of this mutually 
supportive relationship. I have tried to demonstrate in this article that the analysis of language is crucial for an understanding of our present, technology-dominated society - which I think would be salutary for humanities scholars to recognize as well. Predictability is difficult to achieve, even in the sciences whose function it is to make reliable predictions. However, with demonstrable interdependence between the sciences and the humanities throughout both history and prehistory, continued engagement between them on the critical questions of our times must surely be a priority. 


\section{Works cited}

Bate, Jonathan, editor. The Public Value of the Humanities. Bloomsbury, 2011.

Collini, Stefan. What are Universities For? Penguin, 2012.

---. Speaking of Universities. Verso, 2017.

Darwin, Charles. The Descent of Man, and Selection in Relation to Sex. John Murray, 1871. 2 vols.

de Waal, Frans. Are We Smart Enough to Know How Smart Animals Are? Granta, 2016. Dunbar, Robin. Grooming, Gossip and the Evolution of Language. Harvard UP, 1996.

Fitch, W. Tecumseh. "Fossil cues to the evolution of speech." The Cradle of Language, edited by Rudolf Botha and Chris Knight, Oxford UP, 2009.

Greenblatt, Stephen. The Rise and Fall of Adam and Eve. The Bodley Head, 2017.

Harari, Yuval Noah. Sapiens: A Brief History of Humankind. Harvill Secker, 2014.

Herculano-houze, Suzana. The Human Advantage: A New Understanding of How Our Brain Became Remarkable. MIT Press, 2016.

Hublin, J-J, et al. "New fossils from Jebel Irhoud, Morocco and the pan-African origin of Homo sapiens." Nature, vol. 546, no. 7657, 8 June 2017, pp. 289-92.

Marsh, James, director. Project Nim. Icon Films, 2011.

Mithen, Steven. The Singing Neanderthals: The Origins of Music, Language, Mind and Body. Weidenfeld \& Nicolson, 2005.

Migliano, Andrea, et al. "Cooperation and the evolution of hunter-gatherer storytelling." Nature Communications, vol. 8, 5 Dec. 2017, www.nature.com/ articles/s41467-017-02036-8. Accessed 12 Dec. 2017.

Nussbaum, Martha. Not For Profit: Why Democracy Needs the Humanities. Princeton UP, 2010.

Pääbo, Svante. "The human condition. A molecular approach." Cell, vol. 157, no. 1, 2014, pp. 216-26.

Parry, Millman. "Studies in the Epic Technique of Oral Verse-Making: I. Homer and Homeric Style." Harvard Studies in Classical Philology, vol. 41, 1930, pp. 73148.

---. "Studies in the Epic Technique of Oral Verse-Making II. The Homeric Language as the Language of an Oral Poetry." Harvard Studies in Classical Philology, vol. 43, 1932, pp. 1-50.

Pinker, Steven. The Language Instinct: How the Mind Creates Language. Morrow, 1994.

---. The Better Angels of our Nature: The Decline of Violence in History and its Causes. Allen Lane, 2011.

Small, Helen. The Value of the Humanities. Oxford UP, 2013.

Wheeler, Brandon C. "Monkeys crying wolf? Tufted capuchin monkeys use antipredator calls to usurp resources from conspecifics." Proceedings of the Royal Society B, vol. 276, 2009, pp. 3013-18.

Wilson, Edward O. The Social Conquest of Earth. Liveright, 2012.

Wordsworth, William. Poetical Works. Oxford UP, 1936.

Wrangham, Richard \& Dale Peterson. Demonic Males: Apes and the Origins of Human Violence. Bloomsbury, 1996.

Wrangham, Richard. Catching Fire: How Cooking Made Us Human. Profile Books, 2009. 